\title{
Bipolar Nano Impact Transients: Controlling the Redox Potential of Nanoparticles in Solution
}

Jonathan Markham ${ }^{a}$, Neil P. Young ${ }^{b}$, Christopher Batchelor-McAuley ${ }^{a}$ and Richard G. Compton $* a^{*}$

(a) University of Oxford, Department of Chemistry, Physical and Theoretical Chemistry Laboratory, Oxford University, South Parks Road, Oxford, OX1 3QZ (UK)

(b) University of Oxford, Department of Materials, Parks Road, Oxford OX1 3PH (UK)

\section{Corresponding Author}

*Richard G. Compton, E-mail: Richard.compton@chem.ox.ac.uk 


\begin{abstract}
In the bulk solution phase the electrical potential of a single metallic nanoparticle can be controlled by its local chemical environment. In this work it is demonstrated how this nanoparticle 'redox' potential determines - in the case of platinum - the surface functionality of the nanomaterial. Specifically we report that in the aqueous solution phase the surface adsorption of hydrogen on to the platinum interface is inhibited by the addition of iodine to the solution. The iodine does not competitively inhibit the hydrogen deposition, but rather alters the nanoparticle potential, making it comparatively oxidizing. This work evidences this behavior through single nanoparticle electrochemistry and supports these results with characterization using ex-situ energy dispersive X-ray analysis. We show how the electrochemical response depends on the chemical 'redox' state of the nanoparticle in the solution phase; this leads to the first reported example of a bipolar single nanoparticle event characterized by the single nanoparticle impact current transient initially being reductive before switching after ca. 50 milliseconds to being oxidative.
\end{abstract}




\section{INTRODUCTION}

Upon impacting a potentiostated electrode, an electrochemical reaction can be induced to occur at a nanoparticle ${ }^{1-6}$. This redox reaction can be: i) transformative, altering the redox state of the particle or its interface ${ }^{7-8}$, ii) catalytic, whereby the nanoparticle serves to mediate an electrochemical reaction ${ }^{9-12}$ or iii) a mixture of both responses ${ }^{13-14}$. Nanoparticles in suspension move due to Brownian motion, and may randomly collide with a potentiostated interface. If a suitably low-noise electrochemical system is used, this impact can result in a measurable change in the current. Moreover, if a low concentration of particles are present in suspension then it is feasible to measure the electrochemical transients associated with the arrival of individual nanoentities at an electrode held at a controlled potential. As the nanoparticles arrive randomly their responses can be temporally delineated and the measured current transient directly yields information regarding the nature of the reactions occurring at the nanoscale. For a transformative reaction the arrival of a nanoparticle at the surface results in a spike in current. The spike (or blip) arises as the quantity of nano-material arriving at the electrode is finite, hence the nanoreaction rapidly ceases due to the consumption of the reagent (nanoparticle) ${ }^{1-2}$. Conversely, for a catalytic process if the electrochemical reaction proceeds at steady-state then the arrival of a nanoparticle will result in a step in the time-current profile ${ }^{9,11}$. However, in this latter (catalytic) case, other single nanoparticle transient shapes can occur and these may arise when the catalytic activity of the nanoparticle varies as a function of time. An example of this situation is found with the catalytic oxidation of hydrazine at a platinum nanoparticle impacting a mercury electrode. In this case, upon arrival at the electrode surface, the nanoparticle is initially highly catalytically active towards the oxidation processes but becomes inhibited over the time scale of $10 \mathrm{s.}^{10}$ Although the measured single nanoparticle transients give a direct measure of the net 
charge passed to or from individual nanoparticles, the current is necessarily the sum of all processes occurring across the nanostructure. Consequently, in cases where the current transient is due to the occurrence of both transformative and catalytic processes (mixed case iii) it can be challenging to decouple these two contributions ${ }^{9,13}$.

A typical example of a transformative nano-impact reaction is the oxidation of silver to silver (I) ions where the nanoparticle itself changes redox state. ${ }^{15}$ Alternatively, with the use of platinum nanoparticles it was previously demonstrated ${ }^{9,16}$ that the surface functionality of the nanoparticle can be electrochemically altered. A negative electrode potential can drive the reductive deposition of a monolayer of hydrogen or in the case where the platinum nano-material has been pre-exposed to hydrogen - which leads to the chemical formation of an atomic hydrogen monolayer - then these surface hydrogen atoms can be oxidatively removed at positive electrode potentials. Thus the chemical environment of the platinum nanoparticle controls their solution phase redox state and this is directly reflected in their electrochemical behavior; in the case of platinum $\mathrm{H}_{\text {upd }}$ the nano-impact response can be switched from being reductive (due to hydrogen deposition from water) to oxidative (due to removal of surface hydrogen). To date, to the best of the authors' knowledge, all reported nano impact events have been of a single polarity i.e. the impacting of a nanoparticle has resulted in either a net gain (reduction) or loss (oxidation) of electrons throughout the transient. In this work we present the experimental situation where upon impacting the electrode surface the current transient associated with the single nanoparticle reaction changes as a function of time and is at first reductive but then at longer times the overall current switches and becomes oxidative.

This work focuses on the study of porous $70 \mathrm{~nm}$ platinum nanoparticles and both their modification with iodine and the resulting influence of this iodine on the single nanoparticle 
response towards hydrogen. First, the high affinity of the iodine to the platinum surface is evidenced ex-situ though the use of transmission electron microscopy. Second, the electrochemical behavior of bulk polycrystalline platinum towards hydrogen underpotential deposition and the effect that adsorbing iodine has on this is experimentally illustrated. Third, the electrochemical response of platinum nanoparticles towards hydrogen and iodine is outlined. Finally, the work turns to consider how the presence of iodine alters the individual platinum nanoparticle response, demonstrating how under some conditions the impacting nanoparticle can result in a bipolar nano-impact event, where the current is initially reductive (for the first 0.02 seconds) and then becomes oxidative at longer times ( $>0.03$ seconds). "Bipolar" in this context relates to the character of the observed current transients associated with single nanoparticle impacts. For the avoidance of doubt, it does not relate to the so-called "bipolar electrochemistry" in which an electric field induces different electrochemical reactions at different points on a particle surface ${ }^{17}$.

\section{EXPERIMENTAL METHODS}

\subsection{Chemicals}

Hydrogen, oxygen and nitrogen gas ( $\geq 99.98 \%$ ) was supplied from BOC, Surrey, UK. Sulfuric acid and iodine were purchased from VWR Chemicals, Poole, UK, potassium and sodium hydroxide were purchased from Fisher Scientific, Loughborough, UK, potassium nitrate was purchased from Scientific Laboratory Supplies, Nottingham, UK, and citric acid was purchased from Sigma-Aldrich, St Louis, USA. Citrate-capped porous platinum nanoparticles were obtained from nanoComposix, San Diego, CA, with a nominal diameter of $70 \mathrm{~nm}$ (characterisation provided in text), in a solvent of $4 \mathrm{mM}$ aqueous Citrate, and concentration of 
$0.05 \mathrm{mg} \mathrm{mL}^{-1}$. All solutions were prepared with ultrapure water from Millipore, with a resistivity of $18.2 \mathrm{M} \Omega \mathrm{cm}$ at $298 \mathrm{~K}$.

\subsection{Transmission Electron Microscopy}

TEM and HAADF STEM images were obtained using a JEOL-3000F FEGTEM with an accelerating voltage of $200 \mathrm{kV}$. Samples were prepared by removing the citrate capping from the

porous nanoparticles by washing with $\mathrm{NaOH}^{18}$, then exposing to an aqueous solution containing $0.025 \mathrm{mM}$ of molecular iodine for one hour. Nitrogen gas was then bubbled through the resulting solution causing excess iodine to volatise and be removed. Finally $6 \mu \mathrm{L}$ of the nanoparticle suspension was deposited onto a 400 mesh gold TEM grid coated with holey carbon. The grids were stored under vacuum prior to imaging to reduce contamination. The EDS spectra were obtained from 20 equally spaced lines of the electron beam across the nanoparticle. The scanned image had a resolution of 1024 pixels and a dwell time of $10 \mu$ s was used resulting in a pass live time of $3 \mathrm{~s}$, and there were 10 passes for each line.

\subsection{Electrochemistry}

All electrochemical experiments were performed with a three electrode system contained within a Faraday cage. Experiments on a macro-electrode were performed with a $\mu$ Autolab type II potentiostat (Utrecht), using a platinum macro-electrode of diameter $1.66 \mathrm{~mm}$ and a mercurymercurous sulfate reference electrode both from BASi, West Lafayette, IN, and a platinum wire was used as the counter electrode. For experiments on the single nanoparticle scale, the same reference and counter electrodes were used along with a gold microelectrode working electrode of diameter $5 \mu \mathrm{m}$ from ALS, Tokyo, Japan. Potential and impact current measurements were controlled by a lab built highly stabilised low-noise potentiostat which has been previously 
described $^{19}$. Briefly, a low-noise current amplifier (LCA-4K-1G, FEMTO Messtechnik GmbH, Germany) was used. The signal is digitised at $100 \mathrm{KS} / \mathrm{s}$ via a USB data acquisition device (USB6003, National Instruments, Austin, TX) and then filtered digitally by a four-pole Bessel filter to $250 \mathrm{~Hz}$ using a script written in python. This measurement system was designed and is used in order to conserve the total charge passed. This results in 10 current measurements being taken every millisecond, and hence $\sim 3000$ current points per nano-event. All work is reported against vs $\mathrm{Hg} / \mathrm{Hg}_{2} \mathrm{SO}_{4}$ ( $+0.64 \mathrm{~V}$ vs SHE). Both working electrodes were polished with alumina slurries of decreasing sizes: 1.0, 0.3, and $0.05 \mu \mathrm{m}$ from Buehler, Lake Bluff, IL. The macro-electrode was further cleaned electrochemically by repeated cycling (10 cycles) around the platinum oxidation and reduction regions. All electrochemical measurements were thermostated at $25 \pm$ $0.5^{\circ} \mathrm{C}$ for the macro-electrode set up, and $25 \pm 0.1{ }^{\circ} \mathrm{C}$ for the micro-electrode set up.

\section{RESULTS AND DISCUSSION}

This work starts by characterizing, through the use of electron microscopy, the structure of the nominally $70 \mathrm{~nm}$ platinum nanoparticles used in this work. Previous work in the literature has highlighted how this material has a porous structure and hence that the individual nanoparticles have a comparatively large surface area ${ }^{11,20}$.

\subsection{Platinum Nanoparticle Characterisation}

A representative high-angle annular dark-field scanning transmission electron microscopy (HAADF STEM) image of an individual platinum nanoparticle is provided in Figure 1. As can be seen from this image (and the conventional transmission electron microscopy (CTEM) images provided in the SI section 1) the nanoparticle is overall approximately spherical with a dimeter of $71.5 \pm 7.5 \mathrm{~nm}$, but is formed from the aggregation of smaller platinum crystallites which are 3-5 


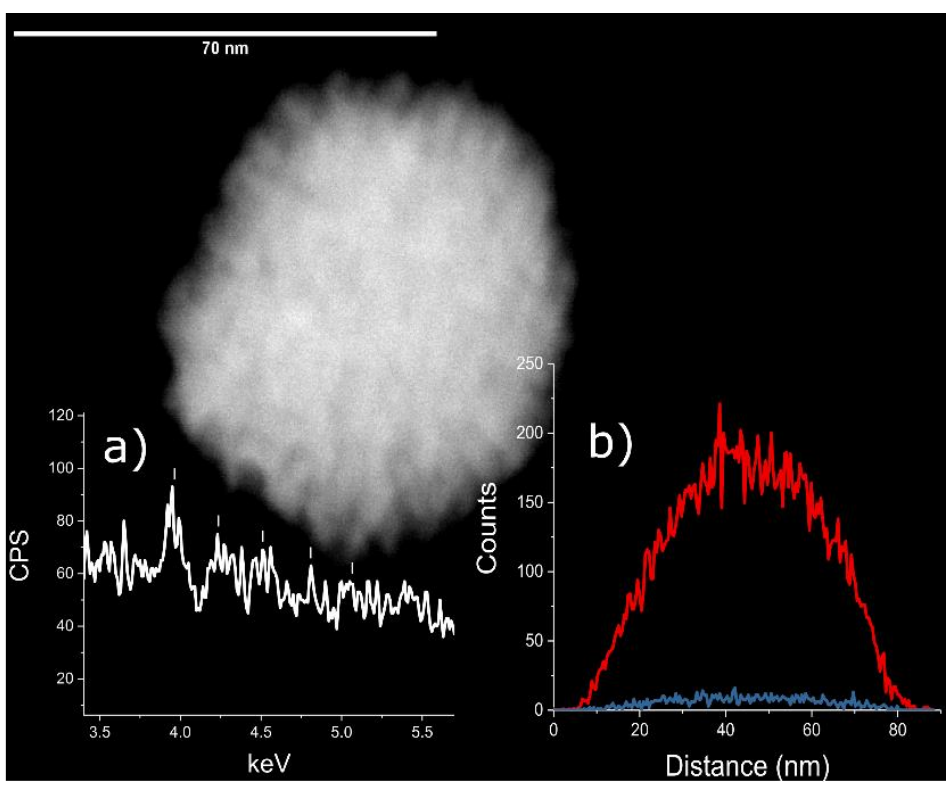

Figure 1: Scanning transmission electron microscope image $(H A A D F)$ of a representative $70 \mathrm{~nm}$ platinum nanoparticle. Inlay left, detail of the EDS spectrum showing the presence of the characteristic iodine peaks. Right, raw x-ray counts per second for the platinum (red) and iodine (blue) for the respective characteristic energies as a function of the distance along the line scan through the center of the nanoparticle..

$\mathrm{nm}$ in size. This aggregate structure leads to the nanoparticle having a comparatively large surface area, as compared to a solid sphere of equivalent overall dimensions ${ }^{11}$. Iodine readily adsorbs to platinum surfaces, forming a monolayer ${ }^{21-28}$. This iodine monolayer is, due to the relatively large size of the iodine atom, incommensurate with the underlying platinum crystallite structure and for single crystal surfaces generally has a surface coverage $\sim 40 \%$ that of the platinum atoms at the interface ${ }^{25,27}$. It is also worth noting, that if the platinum surface has been pre-treated by electrolysis in the presence of protons, the adsorption of iodine is favoured, with surface coverages of up to $62 \%$ having been reported ${ }^{29}$. Due to the strength of the interaction with the platinum, the iodine remains on the surface even under ultra-high vacuum conditions. This iodine - platinum interaction has been found to be similar to that found in the non-labile coordination compounds of halide ions and $\mathrm{Pt}(\mathrm{II})$ or $\mathrm{Pt}(\mathrm{IV})^{22}$, and more detailed analysis on the interaction has been done by Leban and Hubbard, who showed that the halide s and p orbits are 
jointly responsible for bonding ${ }^{30}$. In this work, to image the platinum nanoparticles they were first exposed to an aqueous solution containing $0.025 \mathrm{mM}$ of molecular iodine for one hour prior to imaging, then nitrogen gas was bubbled through the solution, causing excess iodine not adsorbed to the nanoparticles to volatize and be removed from the solution phase. The nanoparticles were subsequently sonicated to re-suspend them in the iodine-free solution and subsequently drop-cast on to a gold TEM grid coated with a holey carbon film. After drying under vacuum for two hours to remove the solvent, the modified TEM grid was used imaged in an electron microscope. Energy dispersive x-ray spectroscopy reveals the presence of the iodine associated with the platinum nanoparticle structure and that this iodine remains after the nanoparticles are removed from the solution phase and are exposed to an ultra-high vacuum. Figure 1 presents a STEM image of a representative nanoparticle, which was scanned by twenty equally spaced lines of the electron beam (see SI section 1 for further details) across the nanoparticle. The inlay a) presents the part of the energy dispersive x-ray spectrum for the line scan showing the characteristic iodine peak at $3.94 \mathrm{keV}$ (L-band) and inlay b) depicts the raw $\mathrm{x}-$ ray count for the platinum (red) and iodine (blue) signals as a function of distance across the nanoparticle. Figure 1 inlay b) clearly evidences the association of the iodine with the platinum structure. The measured iodine to platinum ratio by comparing the integrated areas under their characteristic peaks in the energy dispersive $x$-ray spectroscopy (EDS) spectrum is $1.61 \pm 0.18$ $\%$. For comparison, a perfectly spherical entirely solid particle of the same diameter with a surface monolayer of iodine would be expected to have an iodine to platinum ratio of $0.66 \%$ (assuming a $40 \%$ surface coverage). These two values are not inconsistent, bearing in mind the increase in surface area of a porous nanoparticle as opposed to a perfectly spherical and solid one $^{11,20}$, thus indicating that the iodine coverage on the porous nanoparticle is realistically 
limited to a monolayer. Additionally, the morphology of the nanoparticle was evidenced both in the presence and absence of the surface iodine (see SI section 1 for a CTEM image of nanoparticle not exposed to iodine). Hence, it was observed that the morphology of the platinum nanoparticle was unchanged upon exposure to the iodine. This is consistent with the formation of a surface monolayer of iodine, as the formation of bulk platinum iodide would be expected to have significantly altered the overall nanoparticle morphology. Therefore, due to both this morphological evidence, and the measured iodine platinum ratio, it can be inferred with reasonable confidence that under UHV conditions a monolayer of iodine is formed. Similar results have been reported with the modification of macroscopic single crystal electrodes ${ }^{21,25,31}$. However, we note that in the solution phase the formation of a polyiodide layer on the nanoparticle surface may be possible ${ }^{32-34}$. Having characterized the nanoparticles and their affinity towards iodine, this article now turns to consider the electrochemical behavior of the platinum nanoparticles and iodine. However, first, we will consider the response of a platinum macro-electrode in order to gain a better understanding of the electrochemical processes occurring at platinum nanoparticles.

\subsection{Underpotential Deposition of Hydrogen on Bulk Polycrystalline Platinum}

The behavior of bulk polycrystalline platinum towards hydrogen underpotential deposition $\left(\mathrm{H}_{\text {upd }}\right)$ is a system that has been extensively studied in the literature ${ }^{35-39}$, however, we here overview the results so as to provide a solid framework through which the nano-impacts, which comprise the primary focus of this work, can be understood. To ensure clarity we have, in this and also in the next section, chosen to focus on the study of a macro-electrode as opposed to a glassy-carbon electrode modified with platinum nanoparticles. Although the latter would be feasible, as evidenced in the SI section 2 (Figure S4), the voltammetric $\mathrm{H}_{\text {upd }}$ signals are not as clearly 




Figure 2: Voltammetric response of platinum polycrystalline macro-electrode over the relevant $H_{\text {upd }}$ region in four electrolytes degassed with nitrogen. Green, $20 \mathrm{mM} \mathrm{KOH}$, red, $20 \mathrm{mM} \mathrm{KNO}$, yellow $20 \mathrm{mM}$ citrate buffer, blue $0.1 \mathrm{M} \mathrm{H}_{2} \mathrm{SO}_{4}$. (B) represents the voltammetric response over the $\mathrm{H}_{\text {upd }}$ region in $20 \mathrm{mM} \mathrm{KNO}_{3}$ saturated with hydrogen.

resolved in this case due to the capacitive contribution from the supporting electrode substrate. As such, the basic electrochemistry of hydrogen on platinum is most readily evidenced by studying the macro polycrystalline response. Consequently, Figure 2, depicts the voltammetric response of a platinum polycrystalline macro-electrode, where the electrode has been electrochemically cleaned and activated using voltammetric cycling (see Experimental Methods) then cycled around the relevant $\mathrm{H}_{\text {upd }}$ region in the four different electrolytes which we will consider here: $0.1 \mathrm{M} \mathrm{H}_{2} \mathrm{SO}_{4}, 20 \mathrm{mM} \mathrm{KOH}, 20 \mathrm{mM}$ Citrate buffer, and $20 \mathrm{mM} \mathrm{KNO}$. Under acidic conditions $\left(0.1 \mathrm{M} \mathrm{H}_{2} \mathrm{SO}_{4}\right)$ a characteristic 'double' peak is observed situated in the region of -0.3 -- $-0.6 \mathrm{~V}$ vs $\mathrm{Hg} / \mathrm{Hg}_{2} \mathrm{SO}_{4}{ }^{21}$. In comparison under alkaline conditions this $\mathrm{H}_{\text {upd }}$ signal is both shifted to the potential range of $-0.9---1.2 \mathrm{~V}$ and changes its voltammetric shape. The relevant potential ranges for the different crystal facets $^{40}$ under acid and alkaline conditions are summarized on Figure 2. Under acid conditions the electrochemical $\mathrm{H}_{\text {upd }}$ reaction is: 
$\mathrm{M}+\mathrm{H}_{3} \mathrm{O}^{+}+\mathrm{e}^{-} \rightleftharpoons \mathrm{M}-\mathrm{H}+\mathrm{H}_{2} \mathrm{O}$

where $\mathrm{M}$ represents an unoccupied metallic site. Under alkali conditions the reaction is:

$\mathrm{M}+\mathrm{H}_{2} \mathrm{O}+\mathrm{e}^{-} \rightleftharpoons \mathrm{M}-\mathrm{H}+\mathrm{OH}^{-}$

It is important to recognize that the electrochemical process is more complex than outlined by equations 1 and 2. In reality the $H_{\text {upd }}$ voltammetric peaks arise from competitive adsorption/desorption of $\mathrm{H} / \mathrm{OH}^{40}$; only for the $\mathrm{Pt}(111)$ interface under alkali conditions can these two $(\mathrm{H} / \mathrm{OH})$ processes be clearly resolved from each other (as indicated by the $\operatorname{Pt}(111)$ potential ranges on Figure 2). From Figure 2, the shift in potential of the electrode response in the $H_{\text {upd }}$ region in acid, alkali and buffered (citrate/citric) $\mathrm{pH} 7$ electrolytes can be seen, with the latter electrolyte case showing the hydrogen deposition stripping signal mid-way between that of the alkali and acid conditions. The $\mathrm{H}_{\text {upd }}$ signal is shown to shift in a near Nernstian manner across the full aqueous $\mathrm{pH}$ range, as has been previously evidenced ${ }^{41}$. This is due to reactions 1 and 2 involving protons and hydroxide ions. Hence the $\mathrm{H}_{\text {upd }}$ response is sensitive to the solution phase $\mathrm{pH}$.

The response of the electrode in the fourth electrolyte studied, a $20 \mathrm{mM}$ potassium nitrate solution ( $\mathrm{pH}$ 6.25), but in the absence of additional buffer, is more complex. Under these conditions, the $\mathrm{H}_{\text {upd }}$ signal appears voltammetrically irreversible and distorted, as shown in Figure 2, with only a small peak observed in the anodic scan at $\sim-0.6 \mathrm{~V} v \mathrm{vs} \mathrm{Hg} / \mathrm{Hg}_{2} \mathrm{SO}_{4}$, which is in contrast to the characteristic double peak observed in the other conditions. In this electrolyte, the $\mathrm{pH}$ of the bulk solution is inevitably controlled by the adventitious presence of small amounts of dissolved carbon dioxide despite rigorous degassing with nitrogen ${ }^{42}$, consequently leading to the system having a low buffering capacity. Therefore, it can be inferred that the voltammetric 
distortion we observed relates not to the electron transfer kinetics being sluggish, but arises due to the change in the interfacial $\mathrm{pH}$ during the course of the voltammetric scan. On the anodic scan, the removal of the $\mathrm{H}_{\text {upd }}$ following the process shown in equation 2, is initially limited by the transport of basic anions (such as carbonate or hydroxide) to the interface. However, once a sufficiently positive potential is reached, the interfacial reaction can then proceed via reaction 1 and directly form protons; hence, the small peak observed at $\sim-0.6 \mathrm{~V}$ vs $\mathrm{Hg} / \mathrm{Hg}_{2} \mathrm{SO}_{4}$. On the reverse (cathodic scan) some of these locally produced protons have diffused away from the electrode surface and the deposition of the $\mathrm{H}_{\text {upd }}$ is limited by the mass-transport of protons, either produced electrochemically or present in the bulk solution, to the interface. At more negative potentials the reduction of water to form hydroxide (equation 2) again becomes thermodynamically favorable leading to the small voltammetric feature at $\sim-0.9 \mathrm{~V}$. Similar behaviour in terms of an electrochemical reaction altering the interfacial $\mathrm{pH}$ and the importance of the buffering capacity of the system has been reported ${ }^{42}$.

A further and important feature of this low buffering capacity system is seen when the potential is scanned over a wider potential range. Scanning up to $+0.8 \mathrm{~V}\left(\mathrm{vs} \mathrm{Hg} / \mathrm{Hg}_{2} \mathrm{SO}_{4}\right)$ causes the $\mathrm{H}_{\text {upd }}$ response to become more clearly resolved and to occur at a more negative potential (the corresponding voltammogram is reported in SI section 2). Similarly, as shown in the inlay of Figure 2, in the presence of hydrogen the $\mathrm{H}_{\text {upd }}$ response is - although partially obscured by the presence of the hydrogen oxidation voltammetric wave - shifted anodically. These changes in the location of the $\mathrm{H}_{\text {upd }}$ response are due to the sensitivity of this low buffered system to the occurrence of other electrochemical processes that may alter the local interfacial $\mathrm{pH}$. First, when scanning up to $+0.8 \mathrm{~V}$, at the more positive potentials, platinum oxidation is able to occur. The formation and then subsequent reduction of platinum oxide will cause an increase in $\mathrm{pH}$ local to 
the electrode, which will not be controlled due to the system's poor buffering capacity. Hence the $\mathrm{H}_{\text {upd }}$ signal is shifted to a more negative potential, consistent with an alkaline environment. Second, in the presence of hydrogen, the hydrogen oxidation reaction and the associated production of protons will lower the local interfacial $\mathrm{pH}$ thus causing the $\mathrm{H}_{\text {upd }}$ response to shift anodically. During the hydrogen oxidation process the surface proton concentration is of the order of $1 \mathrm{mM}$. This occurs as the saturated hydrogen concentration is $0.78 \mathrm{mM}^{43}$ and the electrochemical reaction stoichiometrically produces two protons for every hydrogen consumed. However the higher proton diffusion coefficient as compared to that of hydrogen $\left(\mathrm{D}_{\mathrm{H} 2}=4.5 \times 10^{-5}\right.$ $\mathrm{cm}^{2} \mathrm{~s}^{-1}$ and $\left.\mathrm{D}_{\mathrm{H}^{+}}=7.0 \times 10^{-5} \mathrm{~cm}^{2} \mathrm{~s}^{-1}\right)^{44-45}$ limits the local proton concentration at the interface to being of the order of $1 \mathrm{mM}$. Hence during the hydrogen oxidation process and under these poorly buffered conditions the interface is approximately $\mathrm{pH}$. This local shift in the $\mathrm{pH}$ is directly reflected in the positions of the $\operatorname{Pt}(110)$ and $\operatorname{Pt}(100)$ peaks which are found at -0.980 and -0.850 $\mathrm{V}$ respectively (as seen in the inlay of Figure 2) i.e. 390 and $410 \mathrm{mV}$ negative of their positions at $\mathrm{pH} 1\left(0.1 \mathrm{M} \mathrm{H}_{2} \mathrm{SO}_{4}\right)$. Having overviewed the voltammetric behavior of a polycrystalline electrode the article now turns to consider how this $\mathrm{H}_{\text {upd }}$ response is altered in the presence of iodine.

\subsection{Iodine Adsorption on Polycrystalline Platinum}

Unusually, the key feature of iodine adsorption on platinum is that - at least from an electrochemical perspective - its presence is most clearly evidenced indirectly via its effects on other redox systems, as there is no clear voltammetric feature associated with iodine in the potential window of study; most notably iodine blocking $\mathrm{H}_{\text {upd }}$ and inhibiting the onset of platinum oxide formation provide good indirect evidence ${ }^{22}$. Figure 3 depicts the $\mathrm{H}_{\text {upd }}$ region for a polycrystalline macro-electrode under acidic conditions $\left(0.1 \mathrm{M} \mathrm{H}_{2} \mathrm{SO}_{4}\right)$ for both a clean electrode 
(red line) and one which has been exposed for 1 minute to an aqueous solution containing 0.1 $\mathrm{mM}$ of molecular iodine (blue line), and also under alkaline conditions (20 mM KOH) again for clean (yellow) and iodine modified electrode (green). Under acidic conditions the characteristic 'double' peak which is observed for the clean electrode is not seen for the electrode exposed to iodine. Instead, there is a clear blocking of the $\mathrm{H}_{\text {upd, }}$ as there are no peaks observed in this region. Therefore it can be inferred that the iodine inhibits the $\mathrm{H}_{\text {upd }}$ process. However, the situation is markedly different under alkali conditions. Here the $\mathrm{H}_{\text {upd }}$ processes is only marginally altered as shown in Figure 3. There is only a small but reproducible change in the $\mathrm{H}_{\text {upd }}$ voltammetric profile. On the cathodic (forward) scan the $\mathrm{H}_{\text {upd }}$ onset is delayed to a lower potential, and on the anodic (reverse) scan, the magnitude of the $\mathrm{H}_{\text {upd }}$ peaks is decreased. Repeated cycling of the electrode under these alkali conditions ( 10 cycles around the $\mathrm{H}_{\text {upd }}$ region; from -0.8 -- $-1.2 \mathrm{~V}$ vs $\mathrm{Hg} / \mathrm{Hg}_{2} \mathrm{SO}_{4}$ ) leads to the voltammetric profile changing and it becomes identical to the bare

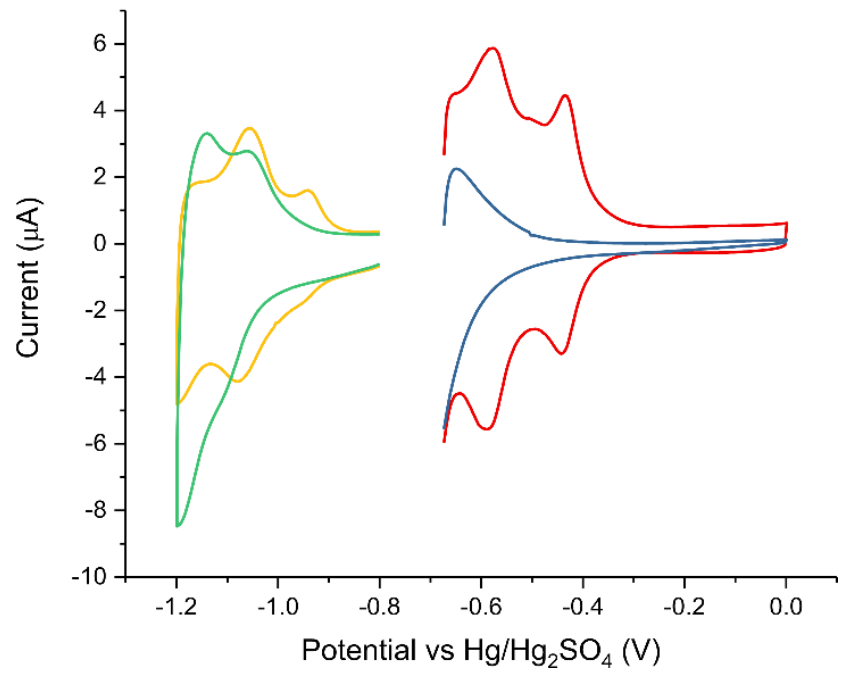

Figure 3: Voltammetric response of platinum polycrystalline macro-electrode over the relevant $H_{\text {upd }}$ region in two electrolytes for the clean electrode and for an electrode exposed to an aqueous solution containing $0.1 \mathrm{mM}$ molecular iodine for one minute. Electrolytes are $0.1 \mathrm{M} \mathrm{H}_{2} \mathrm{SO}_{4}$ (red for clean electrode, blue for iodine modified), and $20 \mathrm{mM} \mathrm{KOH}$ (yellow for clean electrode, green for iodine modified). 
electrode response, thus indicating the slow loss of the iodine from the interface during electrochemical cycling of the electrode. Also it is worth noting for this system that first, as evidenced in the SI section 3, in the presence of iodine the platinum oxide voltammetric response is inhibited as compared to the clean electrode, and second, and most importantly, transfer of the electrode after being in the alkali solution to an acidic solution again voltammetrically shows the same blocking of the $\mathrm{H}_{\text {upd }}$ signal under these conditions as is the case for the non-transfer experiment in Figure 3 (see SI section 3). This provides consistent evidence that even though there is only a slight change in the $\mathrm{H}_{\text {upd }}$ signal under alkali conditions, there is still iodine on the electrode surface. In neither the acid nor alkali conditions is there, in the voltammetric window of study, a clear voltammetric feature directly attributable to the iodine on the surface. Further, the fact that there is only a slight change in the $\mathrm{H}_{\text {upd }}$ response under alkali conditions, indicating that the $\mathrm{H}_{\text {upd }}$ can be deposited onto the electrode whilst the iodine is still present, is relatively strong evidence that the two species do not occupy the same adsorption sites on the interface and can, at least under reductive potentials, co-exist on the platinum surface. Consequently, it would seem that the inhibition by iodine of the $\mathrm{H}_{\text {upd }}$ under acidic conditions is not simply due to competitive adsorption, as may at first sight be erroneously inferred from the results presented in Figure 3.

The above results focus on the influence of the solution phase environment on the voltammetric response of the platinum macro-electrode. However, as will be outlined in the following section the platinum open circuit potential is also distinctly sensitive to the constituents of the aqueous environment, and the following results are of direct importance when considering the behavior of the platinum nanoparticles when present, not at an potentiostated interface, but isolated in the solution phase. 


\subsection{Open Circuit Potential (OCP) of Platinum Macro-electrode}

The OCP of a macroscopic platinum electrode was investigated by submerging a polycrystalline platinum macro-electrode into an oxygenated solution containing $20 \mathrm{mM} \mathrm{KNO}_{3}(\mathrm{pH} 6.25)$ and measuring its open circuit potential against a reference electrode. The potential on the platinum electrode under these conditions was found to be $0.07 \mathrm{~V}$ (see Table 1 for a summary of measured OCP values). In this situation the electrode potential predominantly reflects the redox potential of the oxygen/water couple; however, the reversible oxygen potential of $0.59 \mathrm{~V}$ is not attained due to the slow kinetics of the reaction ${ }^{46}$. Table 1 also presents the potential attained upon removal of the oxygen from the system by degassing the solution with nitrogen, this removal of oxygen leads to an observed decrease in the electrode potential to $-0.10 \mathrm{~V}$. This decrease in potential directly reflects the lower solution phase oxygen concentration - degassing of the solution results in an oxygen concentration of ca. $10 \mu \mathrm{M}^{47}$, and in the absence of other redox active species this residual oxygen may control the open circuit potential of the platinum. Saturating the same solution with hydrogen leads to a further change in potential of the polycrystalline macro-electrode: the OCP shifts reductively to $-0.93 \mathrm{~V}$. This value is essentially that of the reversible hydrogen electrode, which at this $\mathrm{pH}$, has a potential of $-1.01 \mathrm{~V}$ vs $\mathrm{Hg} / \mathrm{Hg}_{2} \mathrm{SO}_{4}$. Furthermore, the addition of hydrogen to the solution both shifts the OCP of the electrode and causes a concomitant change in the electrode surface functionality. Also included in Table 1 is the measured OCP values for a platinum electrode when iodine is additionally present in the solution phase and the potential was found to be $0.07 \mathrm{~V}$. However, in this case the OCP does not solely reflect the standard reduction potential of the iodine/iodide couple; here the electrode attains a mixed redox potential balanced between that of the hydrogen and iodine redox couples (this case will be returned to latter in the text). However, the most important point to 
recognise from this OCP data is that, the potential of the platinum macro-electrode is in part determined by the constituents of the solution phase. Moreover, as will be demonstrated, just as the OCP of the macro-platinum electrode depends on the composition of the solution phase, similarly the potential held on the nanoparticles in the solution phase will be sensitive to their local chemical redox environment. Importantly in the case of nanoparticles it may also be important to consider the role of surfactants and/or capping agents in

\begin{tabular}{|c|c|c|c|c|}
\hline Condition & $\begin{array}{l}\text { Potential vs } \\
\mathrm{Hg} / \mathrm{Hg}_{2} \mathrm{SO}_{4} / \mathrm{V} \\
\end{array}$ & $\begin{array}{l}0.1 \mathrm{M} \mathrm{H}_{2} \mathrm{SO}_{4} \\
(\mathrm{pH}=1.05)\end{array}$ & $\begin{array}{l}20 \mathrm{mM} \mathrm{KNO}_{3} \\
(\mathrm{pH}=6.25)\end{array}$ & $\begin{array}{l}20 \mathrm{mM} \mathrm{KOH} \\
(\mathrm{pH}=12.50)\end{array}$ \\
\hline $\begin{array}{l}\text { Saturated with } \mathrm{N}_{2} \\
\text { Saturated with } \mathrm{H}_{2} \\
\text { Saturated with } \mathrm{O}_{2}\end{array}$ & & $\begin{array}{l}0.03 \\
-0.71 \\
0.21\end{array}$ & $\begin{array}{l}-0.10 \\
-0.93 \\
0.07\end{array}$ & $\begin{array}{l}-0.43 \\
-1.32 \\
-0.38\end{array}$ \\
\hline $\begin{array}{l}\mathrm{I}_{2} \text { in solution, saturated } \\
\text { with } \mathrm{N}_{2} \\
\mathrm{I}_{2} \text { in solution, saturated } \\
\text { with } \mathrm{H}_{2}\end{array}$ & & $\begin{array}{l}0.15 \\
0.13\end{array}$ & $\begin{array}{l}0.19 \\
0.07\end{array}$ & $\begin{array}{l}-0.04 \\
0.00\end{array}$ \\
\hline
\end{tabular}

Table 1: Open circuit potentials measured on a platinum macro-electrode $(d=1.66 \mathrm{~mm})$ in three given electrolytes, saturated with nitrogen, hydrogen or oxygen.

controlling the nanomaterial's redox potential. Here the organic and/or inorganic reagents may serve to either inhibit the interaction of the metallic surface with other solution phase species (such as oxygen), or alternatively be redox active themselves as is likely the situation with thiol containing species. Prior to considering the experimental case where the platinum nanoparticles are simultaneously exposed to both hydrogen and iodine in the solution phase the following section overviews the behavior the platinum nanoparticles solely in the presence and absence of hydrogen gas.

3.5 Platinum $\mathrm{H}_{\text {upd: Nano-impact Events }}$ 

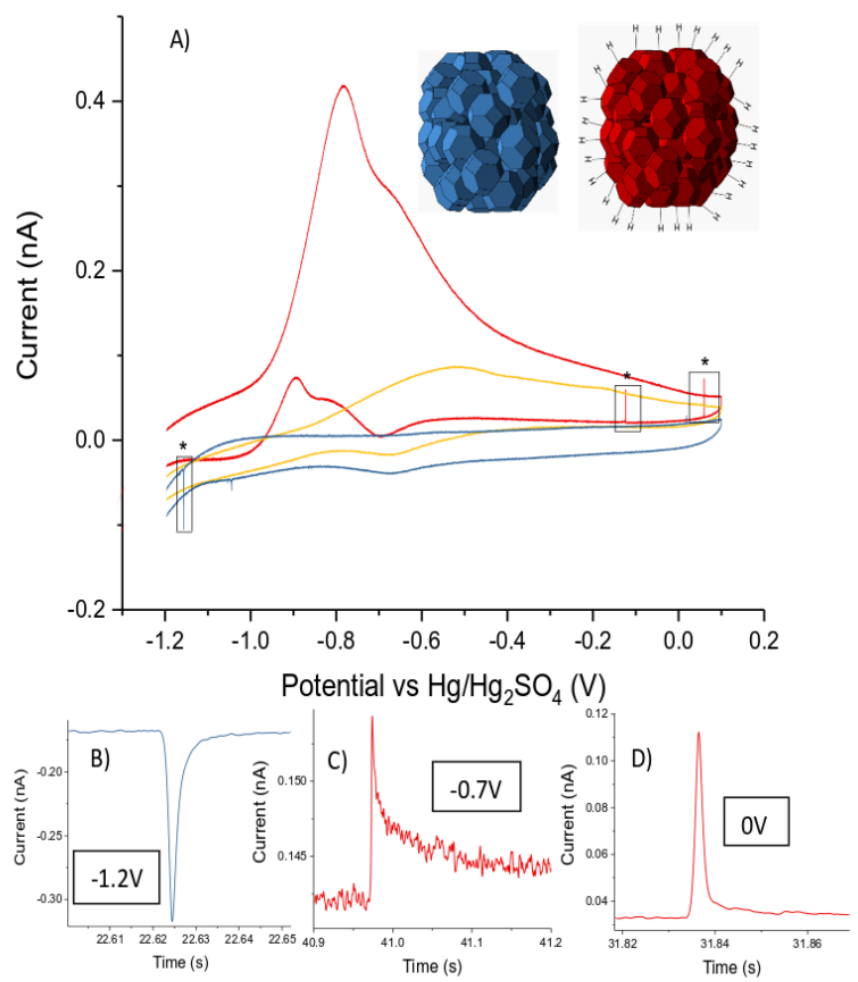

Figure 4: a) Cyclic voltammetric response of a gold microelectrode submerged in a solution containing $20 \mathrm{mM} \mathrm{KNO}$. Red is the response for the electrode in a hydrogen saturated solution in the presence of $3.0 \mathrm{pM}$ of Pt nanoparticles. Yellow depicts the gold response in a solution saturated with hydrogen but in the absence of nanoparticles. Blue is the gold response in a solution saturated with nitrogen but in the presence of $3.0 \mathrm{pM}$ of Pt nanoparticles. b), c) and d) are representative nano-impact features measured at $-1.2,-0.7$ and $0 \mathrm{~V}$ respectively. c) and d) in the presence on hydrogen and $b$ ) in the absence.

The electrochemical deposition of $\mathrm{H}_{\text {upd }}$ at individual nanoparticles has been previously evidenced in the literature ${ }^{9,16,48}$ and this section serves to experimentally provide a concise summary of these results and, further, to apply the nano-impact technique to the study of porous $70 \mathrm{~nm}$ platinum nanoparticles. Here the choice to use these relatively large $70 \mathrm{~nm}$ particles is in part to ensure that their single nanoparticle response is clearly defined and measurable above the background response of the electrochemical system. However, we do caution that extrapolation of these results to nanoparticles of other sizes and dimensions may not be completely facile. Experimentally, a gold micro-electrode (radius $=2.5 \mu \mathrm{m}$ ) was submerged into a solution containing $3.0 \mathrm{pM}$ of the $70 \mathrm{~nm}$ platinum nanoparticles and $20 \mathrm{mM}$ 
$\mathrm{KNO}_{3}$. Figure 4 depicts the voltammetric response of this electrode in the presence of a nitrogen atmosphere (blue line). Here the only notable voltammetric features is the presence of sharp reductive spikes which onset at $\sim-0.6 \mathrm{~V}$ vs $\mathrm{Hg} / \mathrm{Hg}_{2} \mathrm{SO}_{4}$, a representative example of which is given in Figure 4 b), as observed at a potential of $-1.2 \mathrm{~V}$. These spikes are found to have an average charge of $0.30 \pm 0.05 \mathrm{pC}$. These events are ascribed as relating to the deposition of a monolayer of hydrogen on to the platinum nanoparticle interface by the reaction (2) as discussed in the previous section for the nitrate electrolyte. Saturating the same nanoparticle solution with hydrogen (red line) leads to very different signals: the observation of oxidative as opposed to reductive features. These oxidative transients onset at around $-0.8 \mathrm{~V}$ and become significantly sharper at higher anodic potentials. Representative examples of these features can be seen in Figure $4 \mathrm{c}$ and d) observed at -0.7 and $0.0 \mathrm{~V}$ respectively. At $0.0 \mathrm{~V}$ vs $\mathrm{Hg} / \mathrm{Hg}_{2} \mathrm{SO}_{4}$ these oxidative features are clear spikes and are comparable in magnitude to those found reductively (under a nitrogen atmosphere) with an associated charge of $0.26 \pm 0.02 \mathrm{pC}$. These oxidative spikes are ascribed as relating to the oxidative removal of hydrogen from the surface of the nanoparticle, where the platinum interface has become chemically modified by the presence of hydrogen gas in the solution phase by the occurrence of the following reaction:

$2 \mathrm{M}+\mathrm{H}_{2} \rightleftharpoons 2 \mathrm{M}-\mathrm{H}$

Further discussion regarding the magnitude of these nano-impact events and the possible origins of the $\sim 25 \%$ discrepancy in the magnitude of the oxidative and reductive features is explored in the SI section 4. However, assuming a charge density ${ }^{49}$ of $210 \mu \mathrm{C} \mathrm{cm}^{-2}$ this corresponds to an average nanoparticle area of $0.12 \pm 0.010 \mu \mathrm{m}^{2}$. This compares to the value previously reported for these nanoparticles of $0.140 \pm 0.014 \mu \mathrm{m}^{2}$ and gives a roughness factor as compared to a solid spherical particle of the same size of $8.0 \pm 1.1$ using the method as previously described ${ }^{11}$. 
Other notable features of the gold microelectrode behaviour in the presence of hydrogen and platinum nanoparticles (see Figure 4, red line) are, first, the large voltammetric peak centered around $-0.8 \mathrm{~V}$ vs $\mathrm{Hg} / \mathrm{Hg}_{2} \mathrm{SO}_{4}$. In the present conditions the impacting platinum nanoparticles accumulate irreversibly at the gold interface during the course of the voltammetric scan and hence the voltammetric peak at $-0.8 \mathrm{~V}$ increases in magnitude. Subsequent polishing of the electrode causes this voltammetric peak to decrease due to removal of the nanoparticles from the gold interface. A second point of interest is that at these potentials the arrival of nanoparticles to the interface results in the observation of a combined spike and step in the measured current (Fig $4 \mathrm{c})$. Both this voltammetric peak and the step in current relate to the catalytic oxidation of solution phase hydrogen at the platinum nanoparticles. Gold is a poor catalyst for the hydrogen oxidation reaction and as such in the absence of platinum nanoparticles no significant oxidative features are observed (Fig 4 yellow line). Third the nano-impact transients observed at high overpotential, such as at $0.0 \mathrm{~V}$ as shown in Figure $4 \mathrm{~d}$ ). It is notable that here only spikes in current are observed, not spikes and steps, as are observed at lower potentials. This indicates that the platinum catalysed hydrogen oxidation reaction becomes inhibited at high overpotential (ca. $0.2 \mathrm{~V}$ vs $\mathrm{Hg} / \mathrm{Hg}_{2} \mathrm{SO}_{4}$ ). This inhibition is thought to relate to both competitive anion adsorption and oxidation of the platinum surface ${ }^{50}$. Consequently, at higher potentials $(>-0.3 \mathrm{~V})$ the voltammetric response of the platinum modified gold electrode is essentially the same as the unmodified gold surface. This inhibition of the HOR at high overpotentials is an important feature and is of primary importance for understanding the bipolar spikes evidenced later in this article.

The ability to chemically alter the nanoparticle surface, as described in the above section is powerful and reflects how the nanoparticles in the solution phase can be viewed as 'nanoscopic' 
electrodes. ${ }^{51}$ The platinum nano-material is conductive and can hold a potential akin to that of an open circuit potential (OCP) on a macroscopic electrode. Sensitivity of the nanoparticles to their electrochemical environment can cause the change in the platinum nanoparticle nano-impact spikes from being reductive, in the absence of hydrogen, to being oxidative in the presence of hydrogen. The following section serves to evidence the effect of iodine on the platinum nanoparticle response and its influence on the chemical properties of the solution phase nanoparticles.

\subsection{Platinum nano-impacts: Iodine modified particles}

If a solution of platinum nanoparticles are exposed to aqueous phase iodine, do the solution phase nanoparticles become surface modified with a monolayer of iodine? Evidencing the presence or absence of iodine on these solution phase nanoparticles is challenging. Transfer of the material to the ultra-high vacuum conditions required for TEM imaging is possible, as done earlier in this article. However, since the nanoparticle modification is undertaken in the solution phase and the solvent needs to be removed prior to imaging, this leads to some ambiguity in the interpretation of the results; the chemical status of the nanoparticles under ultra-high vaccum conditions does not necessarily reflect that of the solution phase. Electrochemically, as outlined above, the presence of iodine does not lead to any well-defined voltammetric features in the potential window of study, and the presence of the iodine needs to be evidenced indirectly. In the following, the response of platinum nanoparticles in a solution saturated with iodine will be provided. 
Solution phase iodine can be electrochemically reduced at both platinum and gold electrodes, where the standard redox potential for the iodine/iodide couple is $-0.100 \mathrm{~V}$ (vs $\left.\mathrm{Hg} / \mathrm{Hg}_{2} \mathrm{SO}_{4}\right)^{46}$. The SI section 5 presents the voltammetric response of a gold microelectrode in a solution containing $0.1 \mathrm{mM}$ of iodine, evidencing the iodine reduction occurring at potentials more negative than $+0.1 \mathrm{~V}$ with a steady state current of $-4.28 \mathrm{nA}$. This shift in potential from that of the standard potential is due to the absence of iodide in the bulk solution (see SI section 5). To
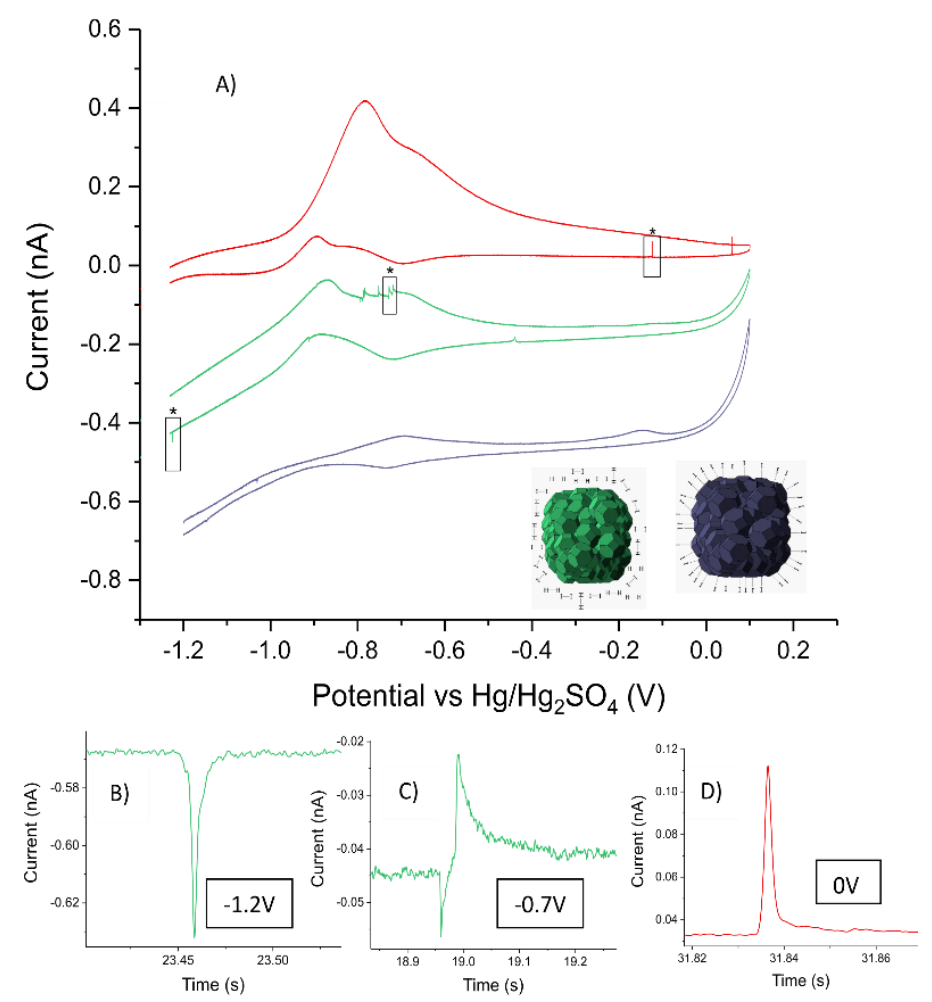

Figure 5 a) Cyclic voltammetric response of a gold microelectrode submerged in a solution containing $20 \mathrm{mM} \mathrm{KNO} 3,3.0 \mathrm{pM}$ of platinum nanoparticles and saturated with hydrogen or nitrogen. Red is the response for the electrode in a hydrogen saturated solution, as shown in Fig 3 and presented here for comparison. Green shows the response for a solution that has been pre-saturated with iodine and also contains hydrogen. Purple shows the response for a solution that has been presaturated with iodine and then degassed with nitrogen. b), c) and d) depict representative nano-impact features measured at $-1.2,-0.7$ and $0 \mathrm{~V}$ respectively. b) and c) are measured in the presence on iodine and d) is in a hydrogen only solution. 
evidence the nanoparticle response to iodine, a solution of platinum nanoparticles as provided (see experimental section) was saturated with iodine using excess solid iodine for 10 minutes. Potassium nitrate solution was then added to give concentrations of $20 \mathrm{mM}$ for the $\mathrm{KNO}_{3}$ and 3.0 $\mathrm{pM}$ for the PtNPs. The resulting solution was then degassed with nitrogen and a gold microelectrode of radius $2.5 \mu \mathrm{m}$ was submerged into the solution, the voltammetric response of which can be seen in figure 5 (purple line). Excess solid iodine was used to saturate the solution as upon degassing, iodine in the solution phase is volatized, hence solid iodine was needed to retain the solution at an iodine concentration close to saturation. Voltammetric scans were run from $-1.2--+0.1 \mathrm{~V}$ (vs $\mathrm{Hg} / \mathrm{Hg}_{2} \mathrm{SO}_{4}$ ). The current is observed to be negative over the full potential range of study due to the presence of iodine which is reduced due to the following reaction:

$\mathrm{I}_{2}+2 \mathrm{e}^{-} \rightleftharpoons 2 \mathrm{I}^{-}$

Contrastingly, the voltammetry for the same conditions, but in the absence of iodine, as was described in the previous section (Figure 4 blue line), shows no background current over the studied potential range. In the presence of iodine and under a nitrogen atmosphere, the observed nano-impacts were clear reductive spikes which occurred at potentials more negative than $\sim-0.6$ V. This is the same response as when only nitrogen is present in the solution, without any iodine (as described in the previous section), indicating that under these conditions the nanoparticle response is unaltered by the presence of iodine. This is consistent with the $\mathrm{H}_{\text {upd }}$ macro-electrode results where under non-buffered conditions (see SI section 3) the $H_{\text {upd }}$ response is only minimally altered by the presence of iodine (akin to the situation observed under alkaline conditions). This is again indicative that the iodine inhibition of the $\mathrm{H}_{\text {upd }}$ is not due to competitive adsorption. At $-1.2 \mathrm{~V}$ the nanoparticle impacts are found to have a charge of $0.33 \pm$ 
$0.04 \mathrm{pC}$, this charge is marginally but not statistically larger than measured solely in the presence of nitrogen.

The response of saturating the same iodine solution with hydrogen instead of nitrogen was also investigated and is shown in the cyclic voltammetric response which is depicted in Figure 5 (green line). Here, the background current is observed to be less negative, and this decrease reflects the partial loss of the iodine from the solution due to volatilisation during the hydrogen bubbling process. However, the first notable feature is that even though hydrogen has been added to the solution, reductive nano-impact events are still observed and, no oxidative events are observed above ca. $-0.5 \mathrm{~V}$ vs $\mathrm{Hg} / \mathrm{Hg}_{2} \mathrm{SO}_{4}$. An example reductive spike as measured at $-1.2 \mathrm{~V}$ in both the presence of hydrogen and iodine is depicted in Figure $5 \mathrm{~b}$ ), with an average charge for these features found to be $0.26 \pm 0.05 \mathrm{pC}$. Furthermore, in the potential range in which the nanoparticles are capable of oxidizing the solution phase hydrogen $(-0.8--0.5 \mathrm{~V})$ distinctive impact features are observed where at first the current transient is negative (reductive) before switching after a few 10s of milliseconds to being positive (oxidative). It is the origin of these bipolar spikes that are the focus of the final section of this work.

\subsection{Bipolar spikes}

Nano-impact events were measured in a solution of $20 \mathrm{mM}$ potassium nitrate and $3.0 \mathrm{pM}$ platinum nanoparticles saturated with hydrogen both in the presence and absence of iodine. The nanoparticles were again saturated with iodine and the nano-impact events investigated at -0.7 and $-0.8 \mathrm{~V}$. Figure 6 compares the shape of the nano-impact events at the two potentials for both in the presence (green) and absence (red) of iodine. In the absence of iodine the nano-impacts are akin in terms of the shape of the nano-impact response to those previously measured using 
smaller $(50 \mathrm{~nm})$ platinum nanoparticles ${ }^{9}$. At $-0.8 \mathrm{~V}$ a simple step in current is observed relating to the catalysis of the solution phase hydrogen by the following redox process:

$\mathrm{H}_{2}-2 \mathrm{e}^{-} \rightleftharpoons 2 \mathrm{H}^{+}$

No concomitant spike is observed for these hydrogen nano-impacts as the potential is not sufficiently oxidizing. At $-0.7 \mathrm{~V}$ a broad spike/step feature is observed with an average charge of $0.48 \pm 0.17 \mathrm{pC}$ (figure $6 \mathrm{a}$ ) red line). At these potentials although an oxidative spike in current is observed, this spike does not solely relate to the removal of the $\mathrm{H}_{\text {upd }}$ signal. The nano-impact response is a convolution of some $\mathrm{H}_{\text {upd }}$ removal and the catalytic oxidation of hydrogen, where the activity of the nanoparticle towards the catalysis process decreases over the course of $10 \mathrm{~s}$ of milliseconds. Evidence for this spike not solely relating to the oxidation of the surface hydrogen is found in the fact that the charge passed during this feature is greater than would be consistent
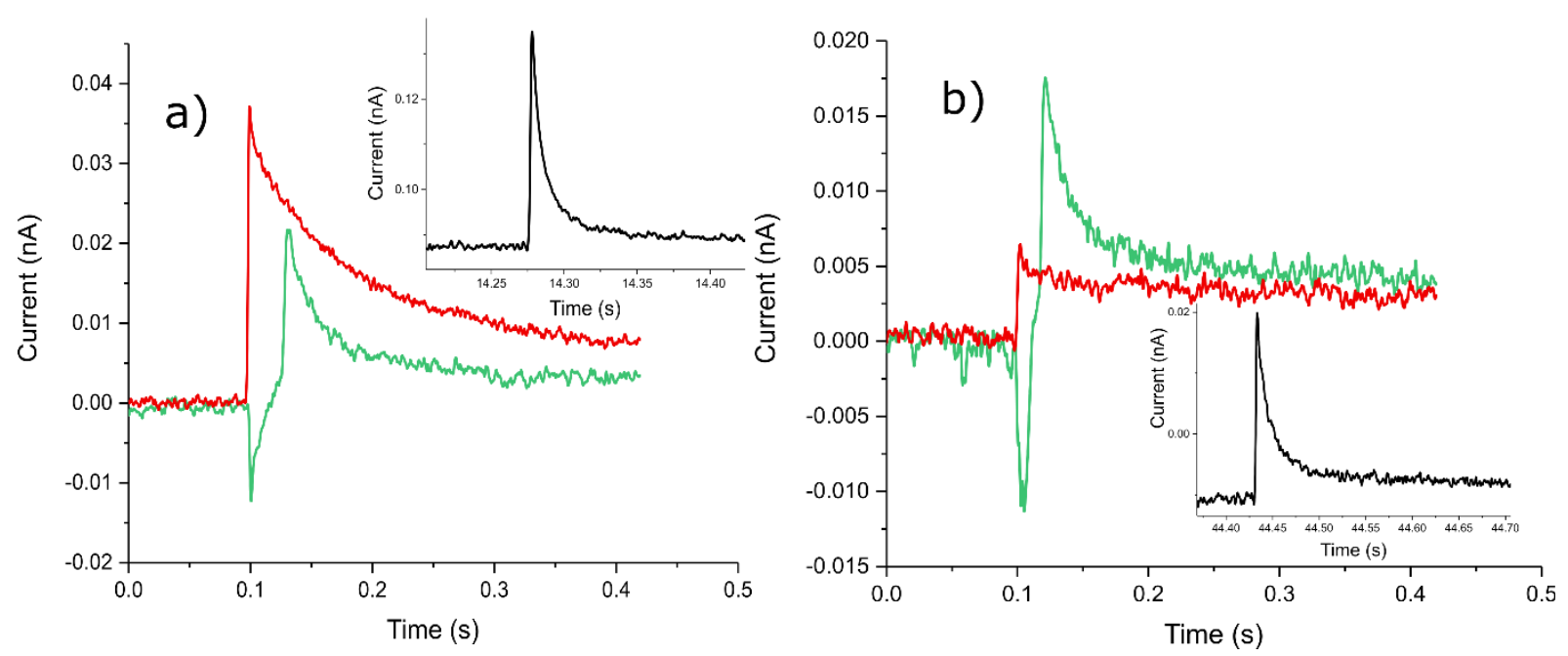

Figure 6: Representative spikes at $-0.7 \mathrm{~V}$ (a) and $-0.8 \mathrm{~V}$ (b) in a $20 \mathrm{mM}$ $\mathrm{KNO}_{3}$ solution with $3 \mathrm{pM} 70 \mathrm{~nm}$ PtNPs for both degassed with hydrogen (red), and pre-saturated with iodine and then degassed with hydrogen (green). The inlays both show representative spikes observed at those potentials and under the iodine and hydrogen conditions for the ca. $40 \%$ of cases where bipolar spikes were not observed. 
with the removal of a monolayer of hydrogen, ca. $0.3 \mathrm{pC}$ is expected for the $\mathrm{H}_{\text {upd }}$ removal, compared to the $0.48 \mathrm{pC}$ which has been measured for this process. In the additional presence of iodine, these nano-impact features are dramatically different. In ca. $60 \%$ of these nano-events a reductive pre-spike is observed. The other $40 \%$ show only oxidative spikes, as shown in the inlays of Figure 6. This variability in impact transients may reflect the sample heterogeneity, and will be expanded upon below. Note, each nanoparticle which impacts the electrode to cause a transient will not only be of different sizes, but different surface structures.

These bipolar transients with reductive pre-peaks are only observable in the case where the nanoparticles have been pre-exposed to iodine prior to the addition of hydrogen to the solution. Again in the presence of iodine the oxidative spike is larger than would be anticipated for the removal of hydrogen (average charge of $0.55 \pm 0.04 \mathrm{pC}$ ) and as evidenced in the previous section in the presence of iodine no oxidative spikes are observed above $\sim-0.5 \mathrm{~V}$, thus strongly indicating that the nanoparticles in the solution phase are not modified with hydrogen when in the presence of both hydrogen and iodine. Consequently, again these oxidative spikes in current measured at -0.7 and $-0.8 \mathrm{~V}$ are thought to relate to the oxidation of hydrogen by the platinum nanoparticle where the particle activity varies over the course of tens of milliseconds.

However, what is the physical origin of the pre-reductive spike? Given the lack of voltammetric features at a macro-electrode attributable to iodine under these conditions (as evidenced in this work), it is unlikely that these spikes relate to the reduction of surface iodine atoms. However insight into the question can be found by considering the OCP of a macroelectrode under comparable conditions, as shown in Table 1. In the case where both iodine and hydrogen are present in the solution phase a potential of $0.07 \mathrm{~V}$ is held on the electrode surface. This potential represents a mixed potential and is a balance between the oxidative and reductive redox couples, 
iodine and hydrogen respectively. At this oxidative potential the electrode surface will not be modified with hydrogen. Consequently, the nanoparticles in solution will, under the same conditions, likely hold a comparable mixed oxidizing potential. Therefore, we can conclude that the initial reductive spikes in Figure 6 represent the reductive deposition of hydrogen onto the nanoparticle surface caused by, upon impact with the electrode, the potential of the particle being shifted from an oxidative to a more reductive potential. This also provides insight into why the polarity of the current changes from being initially reductive to oxidative. Importantly, as

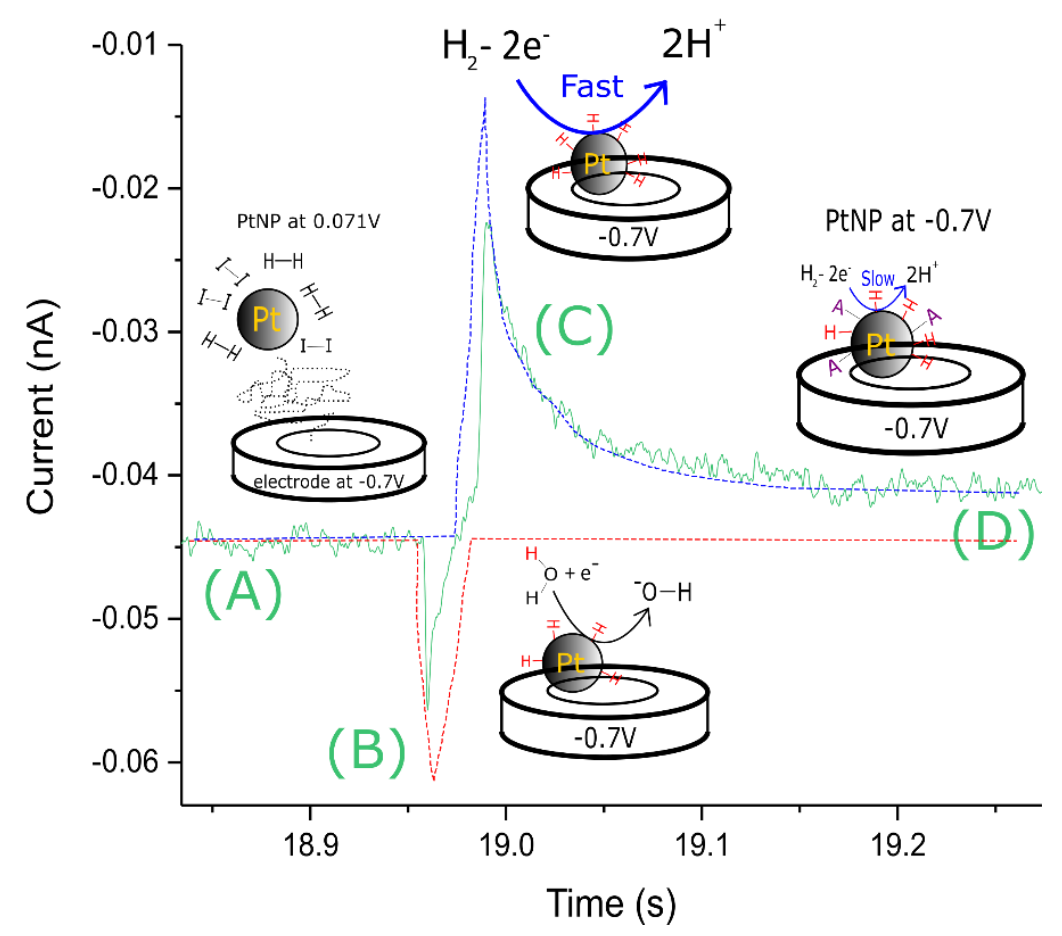


evidenced in Figure 4, the oxidation of hydrogen is not kinetically favourable at high anodic potentials and as such initially after impacting, the nanoparticle is unable to catalyse the hydrogen oxidation reaction due to its high oxidative potential. As the potential of the nanoparticle lowers, with the concomitant reductive deposition of hydrogen, the hydrogen oxidation reaction becomes kinetically favorable at the single nanoparticle resulting in the overall net reaction switching to become oxidative. Figure 7) schematically outlines these processes, depicting how both the nanoparticle's surface functionality and its catalytic activity varies during the course of the nano-event. It shows the partial deposition of hydrogen at the reductive spike (B), the nanoparticle becoming active towards hydrogen oxidation reaction with a full monolayer of hydrogen at the oxidative spike (C), and the spike falling off to a steady state current as the activity of the nanoparticle towards hydrogen oxidation catalysis decreases, leading to a step in current from the initial current observed (D). This decrease in activity to the hydrogen oxidation reaction is most plausibly due to the competitive specific adsorption of anions, possibly iodide, influencing the catalytic reaction rate. Specific adsorption of anions is known to occur at potentials above the potential of zero total charge, PZTC, where anion adsorption is significant, and has been shown to inhibit platinum nanoparticle catalysis of the hydrogen oxidation reaction ${ }^{50,52-53}$. The measured current necessarily represents the sum of both

\footnotetext{
Figure 7: A representative spike at $-0.7 \mathrm{~V}$ in a $20 \mathrm{mM} \mathrm{KNO}_{3}$ solution with 3 pM $70 \mathrm{~nm}$ PtNPs pre-saturated with iodine and degassed with hydrogen (green). The red and blue dashed spikes represent the expected decoupled spikes for the two individual events. At (A) the nanoparticle is in solution and undergoes Brownian walk to the electrode. At (B) the nanoparticle impacts the electrode causing partial deposition of hydrogen as the nanoparticle's potential is reduced. At (C) the nanoparticle becomes active towards hydrogen oxidation catalysis as its potential is further reduced, and there is now a full monolayer of deposited hydrogen. At (D) the nanoparticle's potential has reached that of the electrode, and its activity towards hydrogen oxidation catalysis is reduced due to specific adsorption of anions. This decrease in activity of hydrogen oxidation catalysis leads to the spike in current dying off to reach a steady state.
} 
the oxidative and reductive processes. On Figure 7) we hypothetically depict the separate oxidative (blue) and reductive (red) contributions to the net overall current, could these two separate contributions be measured independently. As is shown, the experimentally measured reductive pre-peak is necessarily smaller than the total reductive contribution. Experimentally at $-0.7 \mathrm{~V}$ the average charge of the reductive pre-peak is found to be $0.096 \pm 0.005 \mathrm{pC}$. This is distinctly smaller than the charge associated with the deposition of a monolayer of hydrogen and the smaller magnitude simply reflects the fact that this measured current relates to the net reaction and not solely the $\mathrm{H}_{\text {upd }}$ reduction process. The fact that a reductive pre-peak is observed indicates that the upon impacting the electrode the rate of the hydrogen oxidation reaction is essentially zero and only increases in magnitude as the nanoparticle potential decreases from its value held in the solution phase towards the potentiostated potential of $-0.7 \mathrm{~V}$. Furthermore given that the measured current is the sum of these two contributions this also provides possible insight into why approximately $40 \%$ of the nano-events do not show this initial reductive prespike. The absence of a reductive pre-spike may reflect the variation in the magnitude of the hydrogen oxidation reaction on individual nanoparticles due to the heterogeneity of the sample. For example, the activity of the nanoparticle to the hydrogen oxidation reaction is known to show a negative size dependency and depend on the available crystal facets ${ }^{50}$. Hence for nanoparticles that are at least initially more catalytically active towards the HOR, the reductive pre-spike may become engulfed by the oxidation process such that the current is positive throughout the entire nano-event.

\section{CONCLUSIONS}


Metallic nanoparticles in suspension can, in some regards, be viewed as electrically isolated 'nanoscopic' electrodes. Being conductive they hold a potential, the value of which is partially determined by the local electrochemical environment of the nanoparticle. Taking platinum as a prime example this work suggests first how the potential of the solution phase nanoparticles can be altered and further how this solution potential alters the nanoparticle's surface functionality. Under a hydrogen atmosphere the platinum nanoparticle holds a reductive potential and becomes modified with a monolayer of hydrogen. The deposition of hydrogen can be fully inhibited by the addition of iodine to the solution. However, this inhibition is not due to competitive adsorption, the ability of both iodine and hydrogen to co-exist on the platinum surface is evidenced electrochemically. This iodine leads to the nanoparticle holding an oxidative as opposed to a reductive potential, inhibiting the surface hydrogen deposition.

From an electrochemical perspective this ability to control the nanoparticle redox state has important consequences. The nano-impact response is, as shown, sensitive to the nanoparticle solution phase potential. In this work it is demonstrated how in the presence of both iodine and hydrogen the platinum nanoparticle holds a relatively oxidizing potential. Upon impacting an electrode that has a more reductive potential the single nanoparticle response is initially reductive, corresponding to hydrogen deposition from water before switching and becoming overall oxidative due to the catalytic oxidation of the solution phase hydrogen. Key to the occurrence of these 'bipolar' single nanoparticle transients is the fact that at higher anodic potentials the platinum catalytic hydrogen oxidation reaction is kinetically inhibited, consequently upon impacting the electrode the rate of the hydrogen oxidation reaction is initially low but increases as the potential of the nanoparticle equilibrates to that of the electrode.

\section{SUPPORTING INFORMATION DESCRIPTION}


SI file contents:

Section 1: Transmission Electron Microscopy Characteristion

Section 2: Underpotential Deposition of Hydrogen

Section 3: Iodine on Polycrystalline Platinum

Section 4: Platinum $\mathrm{H}_{\text {upd: Nano-impacts }}$

Section 5: Voltammetric Response of a Gold Microelectrode in an Iodine Solution

NOTES

There are no conflicts of interest to declare.

\section{ACKNOWLEDGMENT}

There are no acknowledgements that need to be made.

TOC GRAPHIC

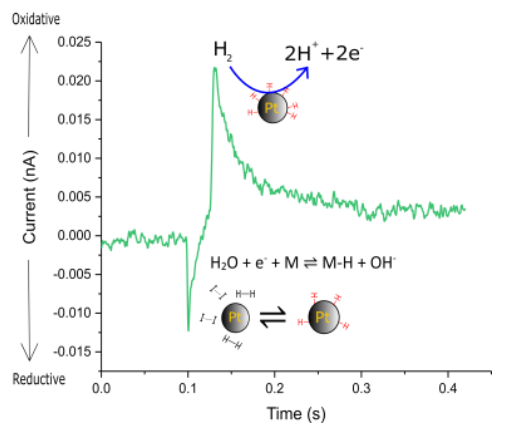

\section{REFERENCES}

1. Sokolov, S. V.; Eloul, S.; Kätelhön, E.; Batchelor-McAuley, C.; Compton, R. G., Electrode-Particle Impacts: A Users Guide. Physical Chemistry Chemical Physics 2017, 19, 2843.

2. Little, C. A.; Xie, R.; Batchelor-McAuley, C.; Kätelhön, E.; Li, X.; Young, N. P.; Compton, R. G., A Quantitative Methodology for the Study of Particle-Electrode Impacts. Physical Chemistry Chemical Physics 2018, 20, 13537-13546.

3. Robbs, P. H.; Rees, N. V., Nanoparticle Electrochemistry. Physical Chemistry Chemical Physics 2016, 18, 24812-24819.

4. Cheng, W.; Compton, R. G., Electrochemical Detection of Nanoparticles by 'NanoImpact' Methods. TrAC Trends in Analytical Chemistry 2014, 58, 79-89.

5. Pumera, M., Impact Electrochemistry: Measuring Individual Nanoparticles. ACS Nano 2014, 8, 7555-7558. 
6. Stevenson, K. J.; Tschulik, K., A Materials Driven Approach for Understanding Single Entity Nano Impact Electrochemistry. Current Opinion in Electrochemistry 2017, 6, 38-45.

7. Zhou, Y.-G.; Haddou, B.; Rees, N. V.; Compton, R. G., The Charge Transfer Kinetics of the Oxidation of Silver and Nickel Nanoparticles Via Particle-Electrode Impact Electrochemistry. Physical Chemistry Chemical Physics 2012, 14, 14354-14357.

8. Giovanni, M.; Ambrosi, A.; Sofer, Z.; Pumera, M., Impact Electrochemistry of Individual Molybdenum Nanoparticles. Electrochemistry Communications 2015, 56, 16-19.

9. Jiao, X.; Batchelor-McAuley, C.; Lin, C.; Katelhon, E.; Tanner, E. E. L.; Young, N. P.; Compton, R. G., Role of Nanomorphology and Interfacial Structure of Platinum Nanoparticles in Catalyzing the Hydrogen Oxidation Reaction. Acs Catalysis 2018, 8, 6192-6202.

10. Dasari, R.; Robinson, D. A.; Stevenson, K. J., Ultrasensitive Electroanalytical Tool for Detecting, Sizing, and Evaluating the Catalytic Activity of Platinum Nanoparticles. Journal of the American Chemical Society 2013, 135, 570-573.

11. Yu, W.; Batchelor-McAuley, C.; Chang, X.; Young, N. P.; Compton, R. G., Porosity Controls the Catalytic Activity of Platinum Nanoparticles. Physical Chemistry Chemical Physics 2019, 21, 20415-20421.

12. Ly, L. S. Y.; Batchelor-McAuley, C.; Tschulik, K.; Kätelhön, E.; Compton, R. G., A Critical Evaluation of the Interpretation of Electrocatalytic Nanoimpacts. The Journal of Physical Chemistry C 2014, 118, 17756-17763.

13. Jiao, X.; Lin, C.; Young, N. P.; Batchelor-McAuley, C.; Compton, R. G., Hydrogen Oxidation Reaction on Platinum Nanoparticles: Understanding the Kinetics of Electrocatalytic Reactions Via "Nano-Impacts". The Journal of Physical Chemistry C 2016, 120, 13148-13158. 14. Xiang, Z. p.; Deng, H. q.; Peljo, P.; Fu, Z. y.; Wang, S. 1.; Mandler, D.; Sun, G. q.; Liang, Z. x., Electrochemical Dynamics of a Single Platinum Nanoparticle Collision Event for the Hydrogen Evolution Reaction. Angewandte Chemie 2018, 130, 3522-3526.

15. Zhou, Y. G.; Rees, N. V.; Compton, R. G., The Electrochemical Detection and Characterization of Silver Nanoparticles in Aqueous Solution. Angewandte Chemie International Edition 2011, 50, 4219-4221.

16. Jiao, X.; Batchelor-McAuley, C.; Young, N. P.; Compton, R. G., Simultaneous Activity and Surface Area Measurements on Single Mesoporous Nanoparticle Aggregates. Physical Chemistry Chemical Physics 2018, 20, 23847-23850.

17. Loget, G.; Zigah, D.; Bouffier, L.; Sojic, N.; Kuhn, A., Bipolar Electrochemistry: From Materials Science to Motion and Beyond. Accounts of Chemical Research 2013, 46, 2513-2523.

18. Moglianetti, M.; Solla-Gullón, J.; Donati, P.; Pedone, D.; Debellis, D.; Sibillano, T.; Brescia, R.; Giannini, C.; Montiel, V.; Feliu, J. M., Citrate-Coated, Size-Tunable Octahedral Platinum Nanocrystals: A Novel Route for Advanced Electrocatalysts. ACS applied materials \& interfaces 2018, 10, 41608-41617.

19. Batchelor-McAuley, C.; Ellison, J.; Tschulik, K.; Hurst, P. L.; Boldt, R.; Compton, R. G., In Situ Nanoparticle Sizing with Zeptomole Sensitivity. Analyst 2015, 140, 5048-5054.

20. Yu, W.; Batchelor-McAuley, C.; Wang, Y.-C.; Shao, S.; Fairclough, S. M.; Haigh, S. J.; Young, N. P.; Compton, R. G., Characterising Porosity in Platinum Nanoparticles. Nanoscale 2019, 11, 17791-17799.

21. Hubbard, A. T., Electrochemistry of Well-Defined Surfaces. Accounts of Chemical Research 1980, 13, 177-184. 
22. Lane, R. F.; Hubbard, A. T., Electrochemistry of Chemisorbed Molecules. Iii. Determination of the Oxidation State of Halides Chemisorbed on Platinum. Reactivity and Catalytic Properties of Adsorbed Species. The Journal of Physical Chemistry 1975, 79, 808-815.

23. Rodriguez, J. F.; Bravo, B. G.; Mebrahtu, T.; Soriaga, M. P., Surface Coordination Chemistry of Noble-Metal Electrodes. Hydrogen/Iodine Ligand (Adsorbate) Substitution at Smooth Polycrystalline Platinum. Inorganic Chemistry 1987, 26, 2760-2763.

24. Thomas, A. E.; Wieckowski, A., Surface Diffusion Limited Desorption of Iodine on a Platinum Electrode? Journal of Electroanalytical Chemistry 1995, 399, 207-212.

25. Felter, T. E.; Hubbard, A. T., L.E.E.D. And Electrochemistry of Iodine on Pt(100) and Pt(111) Single-Crystal Surfaces. Journal of Electroanalytical Chemistry and Interfacial Electrochemistry 1979, 100, 473-491.

26. Lu, F.; Salaita, G. N.; Baltruschat, H.; Hubbard, A. T., Adlattice Structure and Hydrophobicity of Pt (111) in Aqueous Potassium Iodide Solutions: Influence of Ph and Electrode Potential. Journal of Electroanalytical Chemistry and Interfacial Electrochemistry 1987, 222, 305-320.

27. Shu, Z. X.; Bruckenstein, S., Iodine Adsorption Studies at Platinum. Journal of Electroanalytical Chemistry and Interfacial Electrochemistry 1991, 317, 263-277.

28. Clavilier, J.; Albalat, R.; Gómez, R.; Orts, J. M.; Feliu, J. M., Displacement of Adsorbed Iodine on Platinum Single-Crystal Electrodes by Irreversible Adsorption of Co at Controlled Potential. Journal of Electroanalytical Chemistry 1993, 360, 325-335.

29. Wieckowski, A.; Schardt, B. C.; Rosasco, S. D.; Stickney, J. L.; Hubbard, A. T., Preparation of Well-Defined Surfaces at Atmospheric Pressure: Studies of Structural Transformations of I, Ag-Adlattices on Pt (111) by Leed and Electrochemistry. Surface Science 1984, 146, 115-134.

30. Leban, M. A.; Hubbard, A. T., Quantum Mechanical Description of Electrode Reactions: Part Ii. Treatment of Compact Layer Structure at Platinum Electrodes by Means of the Extended Hückel Molecular Orbital Method. Pt (111) Surfaces. Journal of Electroanalytical Chemistry and Interfacial Electrochemistry 1976, 74, 253-275.

31. Baltruschat, H.; Bringemeier, U.; Vogel, R., Scanning Tunnelling Microscopic Investigation of Iodine-Covered Pt Single-Crystal Electrodes. Faraday Discussions 1992, 94 , 317-327.

32. Lane, R. F.; Hubbard, A. T., Electrochemistry of Chemisorbed Molecules. Ii. Influence of Charged Chemisorbed Molecules on the Electrode Reactions of Platinum Complexes. The Journal of Physical Chemistry 1973, 77, 1411-1421.

33. Johnson, D. C., A Study of the Adsorption and Desorption of Iodine and Iodide at Platinum Electrodes in 1.0 M Sulfuric Acid. Journal of The Electrochemical Society 1972, 119, 331.

34. Rutkowska, I. A.; Marszalek, M.; Orlowska, J.; Ozimek, W.; Zakeeruddin, S. M.; Kulesza, P. J.; Grätzel, M., Nanocomposite Semi-Solid Redox Ionic Liquid Electrolytes with Enhanced Charge-Transport Capabilities for Dye-Sensitized Solar Cells. ChemSusChem 2015, 8, 2560-2568.

35. Łosiewicz, B.; Jurczakowski, R.; Lasia, A., Kinetics of Hydrogen Underpotential Deposition at Polycrystalline Platinum in Acidic Solutions. Electrochim. Acta 2012, 80, 292-301. 36. Zolfaghari, A.; Chayer, M.; Jerkiewicz, G., Energetics of the Underpotential Deposition of Hydrogen on Platinum Electrodes: I. Absence of Coadsorbed Species. Journal of The Electrochemical Society 1997, 144, 3034. 
37. Dion, F.; Lasia, A., The Use of Regularization Methods in the Deconvolution of Underlying Distributions in Electrochemical Processes. Journal of Electroanalytical Chemistry 1999, 475, 28-37.

38. Jerkiewicz, G., Electrochemical Hydrogen Adsorption and Absorption. Part 1: UnderPotential Deposition of Hydrogen. Electrocatalysis 2010, 1, 179-199.

39. Gloaguen, F.; Léger, J. M.; Lamy, C., An Electrochemical Quartz Crystal Microbalance Study of the Hydrogen Underpotential Deposition at a Pt Electrode. Journal of Electroanalytical Chemistry 1999, 467, 186-192.

40. Vidal-Iglesias, F. J.; Arán-Ais, R. M.; Solla-Gullón, J.; Herrero, E.; Feliu, J. M., Electrochemical Characterization of Shape-Controlled Pt Nanoparticles in Different Supporting Electrolytes. ACS Catalysis 2012, 2, 901-910.

41. Sheng, W.; Zhuang, Z.; Gao, M.; Zheng, J.; Chen, J. G.; Yan, Y., Correlating Hydrogen Oxidation and Evolution Activity on Platinum at Different Ph with Measured Hydrogen Binding Energy. Nature communications 2015, 6, 1-6.

42. Batchelor-McAuley, C.; Kozub, B. R.; Menshykau, D.; Compton, R. G., Voltammetric Responses of Surface-Bound and Solution-Phase Anthraquinone Moieties in the Presence of Unbuffered Aqueous Media. The Journal of Physical Chemistry C 2011, 115, 714-718.

43. Wilhelm, E.; Battino, R.; Wilcock, R. J., Low-Pressure Solubility of Gases in Liquid Water. Chemical Reviews 1977, 77, 219-262.

44. Agmon, N., The Grotthuss Mechanism. Chemical Physics Letters 1995, 244, 456-462. 45. Ferrell, R.; Himmelblau, D., Diffusion Coefficients of Hydrogen and Helium in Water. AIChE Journal 1967, 13, 702-708.

46. Bard, A. J.; Parsons, R.; Jordan, J., Standard Potentials in Aqueous Solution; CRC Press, 1985; Vol. 6.

47. Cinková, K.; Clark, M.; Sokolov, S. V.; Batchelor-McAuley, C.; Švorc, L.; Compton, R. G., Improving Limits of Detection. Microdisc Versus Microcylinder Electrodes. Electroanalysis 2017, 29, 1006-1013.

48. Defnet, P. A.; Han, C.; Zhang, B., Temporally-Resolved Ultrafast Hydrogen Adsorption and Evolution on Single Platinum Nanoparticles. Analytical chemistry 2019, 91, 4023-4030.

49. Trasatti, S.; Petrii, O. A., Real Surface Area Measurements in Electrochemistry. Pure and applied chemistry 1991, 63, 711-734.

50. Zalitis, C. M.; Kucernak, A. R.; Sharman, J.; Wright, E., Design Principles for Platinum Nanoparticles Catalysing Electrochemical Hydrogen Evolution and Oxidation Reactions: Edges Are Much More Active Than Facets. Journal of Materials Chemistry A 2017, 5, 23328-23338.

51. Henglein, A., Small-Particle Research: Physicochemical Properties of Extremely Small Colloidal Metal and Semiconductor Particles. Chemical reviews 1989, 89, 1861-1873.

52. Zalitis, C. M.; Sharman, J.; Wright, E.; Kucernak, A. R., Properties of the Hydrogen Oxidation Reaction on Pt/C Catalysts at Optimised High Mass Transport Conditions and Its Relevance to the Anode Reaction in Pefcs and Cathode Reactions in Electrolysers. Electrochim. Acta 2015, 176, 763-776.

53. Chen, Q.-S.; Solla-Gullón, J.; Sun, S.-G.; Feliu, J. M., The Potential of Zero Total Charge of Pt Nanoparticles and Polycrystalline Electrodes with Different Surface Structure: The Role of Anion Adsorption in Fundamental Electrocatalysis. Electrochim. Acta 2010, 55, 7982-7994. 